\title{
Determinants of Farm Households' Vulnerability to the Impact of Land Degradation in the Central Omo-Gibe Basin, Ethiopia
}

\author{
Fisseha Seyoum \\ Schools of Agricultural Economics and Agribusiness Management, Haramaya University \\ Jema Haji \\ Schools of Agricultural Economics and Agribusiness Management, Haramaya University \\ Berhanu Geberamedhin \\ International Livestock Research Institute (ILRI), Addis Ababa, Ethiopia \\ Moti Jaleta \\ International Maize and Wheat Improvement Center (CIMMYT), Addis Ababa, Ethiopia
}

\begin{abstract}
Vulnerability to the impacts of land degradation has been frequently reported in Ethiopia. However, the level of vulnerability and its determinants vary in spatial and temporal. The objective of this study was to estimate farm households' vulnerability to the impact of land degradation and its determinants in the Central Omo-Gibe river sub-basin, southwestern Ethiopia. Primary data were collected from 383 farm households using multistage random sampling techniques. The principal component analysis was employed to give different weights for indicators and estimate the households' vulnerability index so as to categorize farm households based on their level of vulnerability. The result showed that $44.91 \%, 39.16 \%$ and $15.93 \%$ of the sample farm households were found to be less, moderately and highly vulnerable to the impact of land degradation, respectively. The ordered logistic regression result showed that age, sex, marital status, family size, dependency ratio, extension service, social participation, livestock ownership, land tenure security, land size and distance to the nearest main road, perceived reduction cropland productivity and plot-level land degradation affected households' vulnerability to the impact of land degradation. Therefore, policymakers and local development practitioners should give priority to the highly vulnerable households focusing on the major factors affecting vulnerability strengthen human, financial, natural and physical including infrastructure and institutional capitals to minimize the impact of land degradation in the study area.
\end{abstract}

Keywords: Land degradation, Vulnerability, Ordered logistic regression, Principal Component Analysis, OmoGibe basin, Ethiopia

DOI: $10.7176 / \mathrm{CER} / 12-7-01$

Publication date:July $31^{\text {st }} 2020$

\section{Introduction}

In Ethiopia, land degradation combined with climate change/variability has been frequently reported to enhance smallholder farmers' vulnerability (Bekabil, 2014). Land degradation and climate change have interrelated and synergistic effects on the causes and results of socio-economic and biophysical vulnerability (Olson and Campbell, 2003; Saguye, 2017). Saguye (2017) showed that in Ethiopia, smallholder farmers use low input and use rain-fed agriculture, weak institutional support combined with persistent land degradation resulted in low crop productivity induced multiple impacts to agricultural system vulnerability. High crop yield loss, acute food insecurity, high loss of productive agricultural land and continual overtime reduction in family income increased farm households' vulnerability that reduces their adaptive capacity (Gashaw et al., 2014). Reduction of farm households' vulnerability or increasing resilience requires understanding the causes, levels, and distribution of farm households' vulnerability over space and time (Olson, 2018).

Though the impact of land degradation and climate change/variability can prevail at different scales from the micro/household to the national/international scales; literature overlooked the local level vulnerability in favor of regional/national scales in the food security and poverty reduction strategy development (Deresa and Legesse, 2015). Basically, vulnerability varies among farm households due to the variation of their adaptive capacity that comes from the variation in livelihood assets holding or the variations of external exposure and sensitivity factors magnitude and nature (Grothmann et al., 2017). Stringer et al. (2009) argued that if a farm community is exposed to the impacts of land degradation or other agricultural system risks that could potentially increase their vulnerability; poorer households are the most at risk of adverse of the impacts.

In Ethiopia in general and in the Central Omo-Gibe River Sub-basin in particular, so far very few research works have been done on vulnerability to climate change/variability. But there are no empirical studies on the vulnerability to the impacts of land degradation at the farm-household level. Therefore, there is a scarcity of 
information for policymakers and local development planners to intervene in reducing vulnerability and increasing farmers' adaptive capacity and resilience against the impacts of land degradation. The objective of this study was, therefore, to examine farm households' vulnerability to the impacts of land degradation and the resultant determinants in the Central Omo-Gibe River Sub-basin, southwestern Ethiopia.

\section{Methodology}

\subsection{Description of the study area}

This study was conducted in three districts (Issera, Tocha, and Konta) of the Central Omo-Gibe River Sub-basin in southwestern Ethiopia. The Sub-basin is located at $6^{\circ} 30^{\prime} \mathrm{N}$ to $7^{\circ} 25^{\prime} \mathrm{N}$ and $36^{\circ} 15^{\prime} \mathrm{E}$ to $37^{\circ} 55^{\prime}$ and covers an area of 5536.66 square kilometers (Teshome, 2016). The area ranges in altitude from 500 to 3000 meters above sea level having three agro-ecologies, namely highland (19.4\%), midland (43.1\%) and lowland (37.5\%).

The area has a bimodal type of rainfall and its annual rainfall ranges from $1200 \mathrm{~mm}$ to $2500 \mathrm{~mm}$. The average temperature of the area ranges from $17.6 \mathrm{C}^{\circ}$ to $28.5 \mathrm{C}^{\circ}$. The land use of the area was $32.69 \%$ cropland, $13.9 \%$ was perennial, 9.29\% was grazing land, $8.5 \%$ was forest land, $22.7 \%$ was a national park and $12.93 \%$ was another land uses. More than $85 \%$ of the area is a mountainous, rugged and fragile ecosystem with more than $35 \%$ sloppy land used for cultivation. This leads to serious land degradation, crop yield loss due to a decline in productivity which resulted in household vulnerability (Zeleke , 2014).

Dawuro and Konta peoples are the most dominant indigenous people in the area. The total projected population of the area is 580,423 (CSA, 2013) out of which $51 \%$ are male and $49 \%$ are female. In the area, subsistence, smallholder based, crop-livestock mixed rain-fed agricultural system and intensive cropland use contributed to accelerated land degradation.

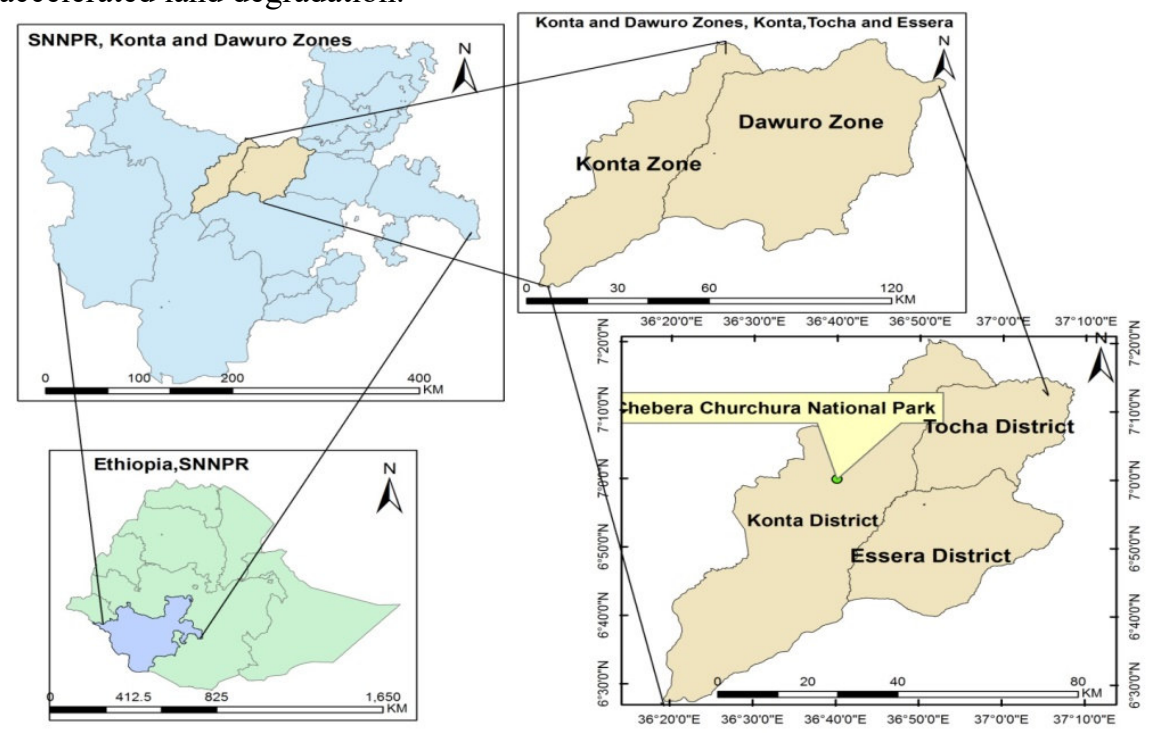

Figure 1. Map of the study area

\subsection{Data sources and methods of data collection}

A combination of qualitative and quantitative data obtained from both primary and secondary data was used for the study. Primary data were collected in face to face interview survey schedule between Octobers and November 2018 from a sample of farm households. The data includes household, socioeconomic and biophysical factors. Semi-structured questioner prepared in English and translated to Amharic, the official language of the study area is used.

The questioner was pre-tested on 20 local farmers for language clarity, coherence, validity, and reliability. The survey was conducted by local development agents who were familiar with local culture and language. Key informants' interviews were conducted to collect basic information on the vulnerability context in the study area. Focus group discussions were also held in each kebele ${ }^{1}$ consisting of 8-12 community members to triangulate the survey results. Rainfall data were collected from the Ethiopian Metrological Agency. Other secondary data were collected from the internet and local government institutions reports.

\subsection{Sampling techniques and sample size}

Primary data were collected using a multistage random sampling procedure. In the first stage, out of the six districts in the central Omo-Gibe Sub-basin, three districts namely: Issera, Tocha, and Konta were randomly selected from

\footnotetext{
${ }^{1}$ This refers to the smallest administrative unit in Ethiopia.
} 
high, mid and lowlands, agro-ecologies respectively to represent the study area. In the second stage, nine kebeles (three from each district) were randomly selected based on probability proportional to size. In the third stage, a total of 383 farm households were randomly selected based on probability proportional to size.

\subsection{Methods of data analysis}

Descriptive statistics such as average, frequency, standard deviation, percentage, index, or score, chi-squared and F-statistics were used to describe the social, economic, and biophysical factors contributing to farm households' vulnerability to land degradation. The ordered logistic regression model was applied to identify factors affecting households' vulnerability to the impacts of land degradation in the study area.

\subsubsection{Measuring vulnerability}

Econometric and indicator approaches are the common approaches to measure vulnerability at different scales. The econometric approach is applied to poverty and development related analysis specifically when the targeted group is affected by single outcome poverty such as vulnerability to expected poverty (Moret, 2014), vulnerability to the low level of expected utility (Olusola, 2014), and uninsured exposure to risk, shock or stress (Senapati, 2019).

When the targeted group is exposed to vulnerability originated from different sources or from the same source of different impacts induced dimensionally to the same targeted group at the same time, the indicators approach vulnerability assessment approach is applied (Sujakhu et al., 2018; Tesso et al., 2012). This approach helps to deduct the most vulnerability contributing indicators and components, to compare the level of vulnerability among the target groups, their distribution over the sample space, and to identify factors influencing different vulnerability levels.

The approach is mostly based on the social vulnerability, economic vulnerability biophysical vulnerability or in combinations called integrated vulnerability assessment approach (Mavhura et al., 2017; Tofu and Dedefa, 2018). IPCC (2001) and UNDP (2010) defined vulnerability as a function of adaptive capacity and the potential impact (exposure and sensitivity). Symbolically, this is indicated in equation 1 :

Vulnerability $=$ (adaptive capacity)-(sensitivity/exposure)

As indicated in equation 1 above, if the adaptive capacity of the household exceeds its potential impact (sensitivity or exposure), the household becomes less vulnerable to the impacts of land degradation and vice-versa. The adaptive capacity of a household is considered as the emergent property of the five types of sustainable livelihood assets such as physical, natural, human and social assets and their entitlements (Sujakhu et al., 2019; Zeleke and Author, 2014). Exposure variables are the direct impact (stimulus) of the external causes such as the severity of land degradation, climate change/variability and crop disease intensity (Zenebe et al., 2016).

Senapati (2019) described sensitivity as the impact of these exposures on crop productivity, livestock performance, food insecurity, poverty and death which are composed of different variables. The model specification further looks like:

$V_{i}=\left(A_{1} x_{1 j}+A_{2} x_{2 j}+\ldots A_{2 n} x_{x j}\right)-\left(A_{1} Y_{1 j}+A_{2} Y_{2 j}+\ldots A_{2 n} Y_{x j}\right)$

Where $\mathrm{V}_{\mathrm{i}}$ is the vulnerability index farm household $\mathrm{i}, \mathrm{A}_{\mathrm{s}}$ are factor score weights extracted from the first principal component analysis (PCA), $\mathrm{X}_{\mathrm{ij}}$ is elements of adaptive capacity and $\mathrm{Y}_{\mathrm{ij}}$ are elements of exposure and sensitivity. The values of $\mathrm{X}$ and $\mathrm{Y}$ are used after normalization using their mean and standard deviation normalization technique (Guilford, 1954) to make the unit of the variable less scale standardized to one that facilitates aggregation of indicators. The normalization process is done to all variables included in the analysis as indicated in equation 3 :

$x_{i j}^{*}=\left(X_{i j}-X_{1 j^{*}}\right) / S_{1}^{*}$

Where: ${ }^{*}{ }_{i j}$ is the indicator score being normalized, $X_{\mathrm{ij}}$ is the value of the $\mathrm{j}^{\text {th }}$ variable of the household $\mathrm{i}$, and $X_{l j^{*}}$ is the mean of $\mathrm{j}$ variable, $\mathrm{S}_{1} *$ is the standardized indicator score of $j$ variable. Normalized $\mathrm{j}$ observed variables of $\mathrm{i}$ farm household matrix of adaptive capacity $\left(\mathrm{X}_{\mathrm{ij}}\right)$ and exposure and sensitivity $\left(\mathrm{Y}_{\mathrm{ij}}\right)$ appear as follows in equation 5 below:

$x_{i j} / y_{i j}=\left(\begin{array}{l}\left(X_{11}+X_{12}+\ldots+X_{2 n}\right)-\left(Y_{11}+Y_{12}+\ldots+Y_{2 n}\right) \\ \left(X_{m 1}+X_{m 2}+\ldots+X_{m n}\right)-\left(Y_{m 1}+Y_{m 2}+\ldots+Y_{m n}\right.\end{array}\right)$

Finally, each household vulnerability index is obtained using equation (5) as follows: 


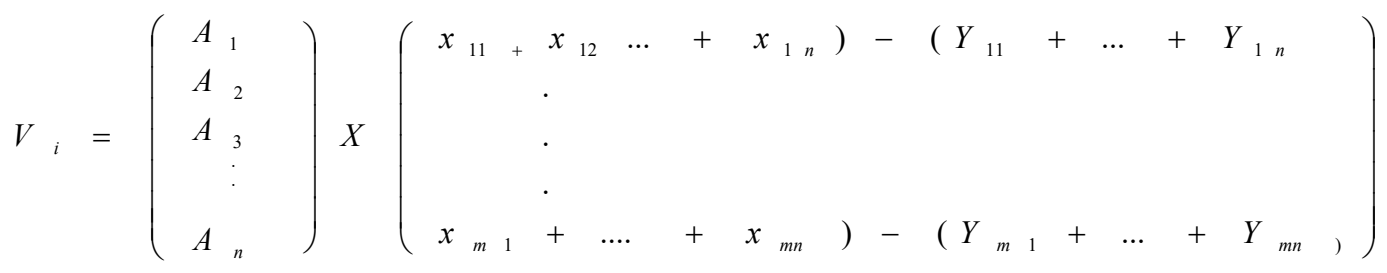

Where $\mathrm{V}_{\mathrm{i}}=$ vulnerability index of $i^{\text {th }}$ farm household; $\mathrm{A}_{\mathrm{s}}=$ computed PCA score from first PCA for each variable; $\mathrm{X}_{\mathrm{i}}=$ Socio-economic adaptive capacity indicator variables of $i$ th farm household and $\mathrm{Y}_{\mathrm{i}}$ is exposure or sensitivity indicator variables of the $i^{\text {th }}$ farm household.

After each household vulnerability index (HVI) is constructed, the index was categorized into different vulnerability levels based on the mean and standard deviation of the index to classify households into three vulnerability categories (low, moderate and high).

\subsubsection{Econometric model specification}

Qaisrani et al. (2018) argued that factors contributing to the household's vulnerability diminish the adaptive capacity for self-protection, block access to, and delay recovery from the stresses or greater frequency and magnitude of land degradation. On the other hand, variables that contribute to increasing households' adaptive capacity, resilience, shorten the time of recovery.

In this study, to identify factors affecting households' vulnerability levels to the impacts of land degradation, the ordinal logistic regression model was used. This model is applied when the outcome variable is ordinal in scale and more than two categories exist as in this study, (1) less vulnerable category meaning that the difference between adaptive capacity and potential impact is significantly positive, (2) moderately vulnerable category meaning that the difference between their adaptive capacity and potential impact is nearly zero, and (3) highly vulnerable meaning that the difference between adaptive capacity and potential impact is significantly negative. The model analysis helps to identify factors contributing to vulnerability or decrease the adaptive capacity/resilience of the farm households (Greene, 2003). The reduced form of the ordered logistic regression model is given by:

$\mathrm{Y}_{\mathrm{i}}^{*}=\beta \mathrm{X}_{\mathrm{ij}}+\mathrm{u}_{\mathrm{ij}}$

and

$$
Y_{i}=j \text { if } M_{j-1}<Y^{*}{ }_{i} \leq \mu_{j}
$$

Where: $\mathrm{Y}$ is the category of vulnerability and involves ordered outcome variables that are, $\mathrm{Y}=1$ less vulnerable, $\mathrm{Y}=2$ is moderately vulnerable, and $\mathrm{Y}=3$ is highly vulnerable. The $\mathrm{X}_{\mathrm{ij}}$ are the explanatory variables, $\beta$ s are parameters to be estimated, and $\mathrm{u}_{\mathrm{ij}}$ is the disturbance term. $\mathrm{Y}^{*}$ is the unobserved variable, but what we observed in this study is:

$$
\begin{aligned}
& \mathrm{Y}=1 \text { if } \mathrm{Y}^{*} \leq \mu_{2} \\
& \mathrm{Y}=2 \text { if } \mu_{2}<\mathrm{Y}^{*} \leq \mu_{3} \\
& \mathrm{Y}=3 \text { if } \mu_{3}<\mathrm{Y}^{*}
\end{aligned}
$$

$\mu$ s are the extremely imposed endpoints of the observed categories.

Given the cumulative normal function $\Phi\left(\beta^{\prime} x\right)$, the probabilities can be shown, thus, probability:

$\operatorname{Pr}(\mathrm{Y}=1$ or less vulnerable $)=\Phi\left(-\beta^{\prime} \mathrm{x}\right)$,

$\operatorname{Pr}(\mathrm{Y}=2$ or moderately vulnerable $)=\Phi\left(\mu_{2}-\beta^{\prime} \mathrm{x}\right)-\Phi\left(\mu_{3}-\beta^{\prime} \mathrm{x}\right)$

$\operatorname{Pr}(\mathrm{Y}=3$ or highly vulnerable $)=1-\Phi\left(\mu_{3}-\beta^{\prime} \mathrm{x}\right)$

The marginal effect is given by:

$$
\frac{\Delta p r(y=m / x}{\Delta X_{K}}=\operatorname{Pr}\left(y=m / X, X_{K}=X_{S}\right)-\operatorname{Pr}\left(y=m / X, X_{K}=X_{S}\right)
$$

Where is the probability that changes vulnerability levels, $y=m$, given $X$, by assigning a specific value to $X_{K}$. The change in the probability is interpreted as when $\mathrm{X}_{\mathrm{K}}$ changes from $\mathrm{X}_{\mathrm{S}}$ to $\mathrm{X}_{\mathrm{E}}$ in one unit, the predicted probability of outcome changes by, holding all other variables constant.

\section{Results and Discussion}

\subsection{Socio-economic and biophysical factors affecting households' vulnerability}

Variables influencing households' vulnerability to the impacts of land degradation including households' social, 
economic and biophysical factors presented in Table 1, were selected based on theoretical foundation and empirical literature review (Mavhura et al., 2017; Tesso, 2013; Tsue et al., 2014). Furthermore, the indicators were contextualized to the local status using key informants' interviews and focus group discussions. Results show that $3.1 \%$ of the households had a household head aged more than 64 years while $16.2 \%$ of the sample households were female-headed households. Out of the sample households, $14.9 \%$ were single household heads including divorced and widowed. The majority of the farmers, $51.2 \%$ had less than ten years of farming experience in the study area.

In the study area, $55.1 \%$ of the sample households participated in less than three social organizations ${ }^{1}$. Furthermore, the majority of the farm households $(71.5 \%)$ had more than five family members (the national average). Out of the total sample households, $48.1 \%$ were illiterate and $77.3 \%$ had no early warning information. Only $17 \%$ of the farm households participated in non-agricultural income-generating activities showing that there is less alternative livelihood strategies in the study area. About $39 \%$ of the households' annual agricultural income is less than 11000.00 Birr. Though the area is conducive for livestock production, about $61 \%$ of the sample farm household heads had less than five livestock measured in TLU. Table 1 also shows that only $13.3 \%$ and $20.2 \%$ of the sample households have access to credit and extension services, respectively.

The survey result also indicated that $37.3 \%$ of the sample farmers travel more than one hour to reach the nearest main road. The study area is the spot of wildlife biodiversity, $59 \%$ of the farm households had a conflict with the wildlife damaging crop and consuming livestock. In the study area, the majority of the farm households (78.8\%) perceived the severity of land degradation, $96.6 \%$ perceived more than $10 \%$ plot level yield reduction in recent years and $80.2 \%$ perceived increase in temperature. In addition, $40 \%$ of the farm households in the study area perceived drought in the past five years.

Table 1. Socio-economic and biophysical factors affecting households' vulnerability

\begin{tabular}{|c|c|c|}
\hline Variable & Percentage & Hypo. sign \\
\hline \multicolumn{3}{|l|}{ 1. Social vulnerability variables } \\
\hline Age of the household head ( $>64$ years) & 3.1 & + \\
\hline Sex of the household head (Female) & 16.19 & + \\
\hline Marital status (Single, divorced or widowed) & 14.9 & + \\
\hline Family size $(>5)$ & 71.5 & + \\
\hline Farm experience $(<10$ years $)$ & 51.2 & + \\
\hline Dependency ratio $(>1)$ & 23.78 & + \\
\hline Literacy status (Illiterate) & 48.6 & + \\
\hline Social participation $(<3$ social organizations) & 55.1 & + \\
\hline \multicolumn{3}{|l|}{ 2. Economic vulnerability indicators } \\
\hline Early warning information (No) & 77.3 & + \\
\hline Non-farm income (No) & 83.03 & + \\
\hline Agricultural income $\left(<11,000 \mathrm{Birr}^{2}\right)$ & 39.2 & + \\
\hline Livestock size $(<5$ TLU) & 61.4 & + \\
\hline Perceived land tenure security (No) & 29.77 & + \\
\hline Access to credit (Yes) & 13.3 & + \\
\hline Distance to the nearest main road ( $>1$ hour) & 37.2 & + \\
\hline Access to agricultural axtension (No) & 20.2 & + \\
\hline \multicolumn{3}{|l|}{ 3. Biophysical vulnerability indicators } \\
\hline Perceived plot level cropland productivity decline $(>25 \%)$ & 67.6 & + \\
\hline Perceived cropland degradation (Yes) & 78.8 & + \\
\hline Human-wildlife conflict (Yes) & 59.5 & + \\
\hline Perceived change in temperature (Yes) & 80.2 & + \\
\hline Perceived change in rainfall (Yes) & 86.95 & + \\
\hline
\end{tabular}

Note: TLU, tropical livestock unit (1 TLU $=250 \mathrm{~kg}$ live animal weight).

Source: Survey dataown computataion, 2019.

\subsection{Impacts of land degradation}

Results presented in Table 2 show farm households' perception of the impacts of cropland degradation by districts. The results show that $44.13 \%, 16.71 \%, 32.11 \%$ and $7.05 \%$ perceived food insecurity, a decline in income, a decline in farm productivity and loss of farmland, as the impacts of land degradation in the study area, respectively. The

\footnotetext{
${ }^{1}$ The social organizations in the study area include "idir", "mehaber", etc. "Idir" is an association established among neighbors or workers to raise funds that will be used during emergencies, such as death within these groups and their families while "Mehaber" is just "a social gathering of friends or family".

${ }^{2}$ It refers to the absolute poverty level in Ethiopia.
} 
chi-squared test result indicated that there is a significant difference among farm households in the three districts in terms of the perceived food insecurity and the decline in productivity impacts of land degradation. Table 2. Impact of cropland degradation on households by district

\begin{tabular}{|c|c|c|c|c|c|}
\hline \multirow[t]{2}{*}{ Impacts of land degradation } & \multicolumn{3}{|c|}{ District } & \multirow[t]{2}{*}{ Total sample } & \multirow[t]{2}{*}{$\chi^{2}$-value } \\
\hline & Konta & Tocha & Issera & & \\
\hline Food insecurity & $46(32.62)$ & $71(50.00)$ & $52(52.00)$ & $169(44.13)$ & $12.07 * * *$ \\
\hline Decline in income & $25(17.73)$ & $25(17.61)$ & $14(14.00)$ & $64(16.71)$ & 0.72 \\
\hline Decline in farm productivity & $60(42.55)$ & $37(26.06)$ & $26(26.00)$ & $123(32.11)$ & $11.15 * *$ \\
\hline Loss of farmland & $10(7.09)$ & $9(6.34)$ & $8(8.00)$ & $27(7.05)$ & 0.25 \\
\hline
\end{tabular}

Source: Own computation 2019.

\subsection{Measuring farm households' vulnerability levels}

Before measuring vulnerability, the Kaiser-Meyer-Olkin (KMO) sample adequacy, Bartlett's Sphericity data fit, and Chronbach's Alpha internal consistency tests were conducted. The test results in Table 3 show that the KMO test value score of 0.65 implies that the correlation is greater than half which implies that there is a strong correlation among the selected variables in affecting vulnerability to the impacts of land degradation (Mavhura et al., 2017). The significance of Bartlett's Sphericity statistic $(\mathrm{df}=2206$; Sig. $=0.000)$ shows that the data fit the model well. Chronbach's alpha test score of 0.586 which is above 0.5 indicates the internal consistent validity of the variables used in the analysis (Qaisrani et al., 2018). The result of all the three tests shows that the selected variables are appropriate in the PCA weight extraction and component-based analysis.

Table 3. Kaiser-Meyer-Olkin (KMO), Bartlett and Cronbach alpha test results

\begin{tabular}{lc}
\hline Test type & Test score value \\
\hline Kaiser-Meyer-Olkin (KMO) & 0.65 \\
Bartlett test of sphericity & $2205.86^{* * *}$ \\
Cronbach coefficient score & 0.59 \\
\hline
\end{tabular}

Source: Own computation (2019)

Table 4 shows the result of the first PCA loading score (weight) of social, economic and biophysical variables.

The factor score (weights) of the first PCA was positively associated with the majority of the selected indicator variables under adaptive capacity, exposure, and sensitivity. Holding exposure and sensitivity constant, a negative index shows the households to have low adaptive capacity when compared to a positive index and vice versa.

Table 4. Factor scores (weight) for the first PCA

\begin{tabular}{lc}
\hline Variables & Factor scores (weight) \\
\hline Age of the household head ( $>$ 64 years) & 0.579 \\
Sex of the household head (Female) & 0.182 \\
Marital status (Single including divorced and widowed) & 0.048 \\
Family size $(>5)$ & -0.100 \\
Farm experience $(<10$ years ) & 0.169 \\
Dependency ratio $(<1)$ & 0.052 \\
Literacy status (Illiterate) & -0.523 \\
Social participation $(<3$ organizations) & -0.069 \\
Early warning information (No ) & -0.063 \\
Non-farm income (No) & 0.175 \\
Agricultural income (<11,000 Birr) & 0.083 \\
Livestock size (<5 TLU) & 0.081 \\
Perceived land tenure security (No) & 0.111 \\
Access to credit (No) & -0.178 \\
Farm size & \\
Distance to the nearest main road (>1 hour) & -0.192 \\
Agricultural extension access (No) & -0.028 \\
Plot level cropland productivity decline ( $>25 \%)$ & -0.192 \\
Perceived cropland degradation (Yes) & -0.014 \\
Human-wildlife conflict (Yes) & -0.048 \\
Perceived change in temperature (Yes) & -0.146 \\
Perceived change in rainfall (Yes) & -0.258 \\
\hline Source: Survey result, PCA statistical anlysis,2019. & \\
\hline
\end{tabular}

Source: Survey results, PCA statistical analysis,2019.

In the computation of vulnerability index, as indicated in equation 2, indicators of adaptive capacity are variables related to positive first PCA and exposure and sensitivity are indicators related to negative first PCA. The variables considered as adaptive capacities such as age, sex, education status, marital status, farming 
experience, conflict on farmland, participation in non-agricultural income-generating activities, land security, early warning information system and livestock ownership. However, all the negative variables in the first PCA such as social participation, family size, literacy status, access to credit, distance to the nearest main road, human-wildlife conflict, perceived cropland degradation, the perceived decline in farm productivity, and perceived change in temperature fall underexposure or sensitivity.

Sample households were classified into three categories based on their relative vulnerability index: less vulnerable, moderately vulnerable and highly vulnerable. Table 5 shows the classification result was based on the mean and standard deviation of the constructed vulnerability index and results show that the majority $(69.45 \%)$ of the sampled households fall within a moderately vulnerable category having vulnerability indices ranging from 1.77 to 1.76 . Out of the total sample households, $14.62 \%$ were less vulnerable whose vulnerability indices range from 1.76 to 5.86 , while the highly vulnerable households were those whose vulnerability indices vary from -1.78 to -2.29 and constitute $15.93 \%$ of the total sample households. Results show that more than two-thirds of the farm households are moderately vulnerable to the impacts of land degradation indicating the need to take appropriate policy measures to reverse the situation. Results also show that the average vulnerability index of less vulnerable, moderately vulnerable and highly vulnerable were $2.75,0.37$ and -1.28 , respectively.

Table 5. Classification of sample households according to their vulnerability indices

\begin{tabular}{llccc}
\hline Vulnerability levels & Households vulnerability status & HVI & Average & Percent \\
\hline Less vulnerable & Vulnerable, but still able to cope & 1.76 to 5.86 & 2.75 & 14.62 \\
Moderately & Needs urgent but temporary external & -1.77 to 1.76 & -0.37 & 69.45 \\
vulnerable & assistance to recover from vulnerability & & & \\
Highly vulnerable & Emergency level & -1.78 to -2.29 & -1.28 & 15.93 \\
\hline
\end{tabular}

Source: Own computation, 2018/19

The results of households' vulnerability distribution by sampled districts presented in Table 6 show that $19.01 \%, 17.02 \%$ and $10.00 \%$ in Tocha, Knota and Issera districts were highly vulnerable households, respectively. However, $23.00 \%, 12.68 \%$ and 10.64\% from Issera Tocha, and Konta districts, respectively were less vulnerable. Moderately vulnerable households constitute $72.34 \%, 68.31 \%$ and $67.00 \%$ in Konta, Tocha and Issera districts, respectively. Table 6 also shows that there is a statistically significant difference in terms of vulnerability among the three districts in the study areas.

Table 6. Households' vulnerability distribution by districts

\begin{tabular}{lccccc}
\hline \multirow{2}{*}{ Vulnerability group } & \multicolumn{5}{c}{ District } \\
\cline { 2 - 5 } & Konta & Tocha & Issera & Total & $\chi^{2}$-value \\
& $(\mathrm{N}=141)$ & $(\mathrm{N}=142)$ & $(\mathrm{N}=100)$ & $(\mathrm{N}=383)$ & \\
\hline Less vulnerable & $15(10.64)$ & $18(12.68)$ & $23(23.00)$ & $56(14.62)$ & $7.85^{* *}$ \\
Moderately vulnerable & $102(72.34)$ & $97(68.31)$ & $67(67.00)$ & $266(69.45)$ & 0.93 \\
Highly vulnerable & $24(17.02)$ & $27(19.01)$ & $10(10.00)$ & $61(15.93)$ & 3.76 \\
Total vulnerability & $141(36.81)$ & $142(37.01)$ & $100(26.11)$ & $383(100.00)$ & $20.41 * * *$ \\
\hline
\end{tabular}

Notice: Values out and in the brackets are frequency and standard deviation, respectively. $* * *, * *$ and $* 1 \%, 5 \%$ and $10 \%$ respectively.

Source: Own computation, 2019.

\subsection{Description of Explanatory Variables by Vulnerability Levels}

The statistical description for model variables by households' vulnerability levels presented in Table 7 shows the relationships among households' vulnerability levels and their social, economic and biophysical explanatory variables. The description result shows that the majority of the vulnerable households were female-headed households, households having no early warning information; households whose head had less than ten years of farming experience and a single marital status headed household. Moreover, households who participated in less than three social institutions, had low annual agricultural income, perceived temperature, rainfall, and productivity decline higher than $25 \%$ per plot. By contrast, the majority of the less vulnerable households were households whose average family size was greater than five persons, households who do not feel secure in the land tenure system, perceived wildlife conflict, perceived in average climate change and perceived h cropland degradation. 
Table 7. The statistical description of model variables by households' vulnerability levels

\begin{tabular}{|c|c|c|c|c|}
\hline \multirow[b]{2}{*}{ Vulnerability variables } & \multicolumn{3}{|c|}{ Vulnerability categories } & \multirow[b]{2}{*}{$\chi^{2}$-value } \\
\hline & $\begin{array}{c}\text { Less } \\
(\mathrm{N}=56)\end{array}$ & $\begin{array}{l}\text { Moderate } \\
(\mathrm{N}=266)\end{array}$ & $\begin{array}{l}\text { High } \\
(\mathrm{N}=61)\end{array}$ & \\
\hline Age of the household head (>64yrs) & $4(7.1)$ & $8(3.0)$ & $1(1.6)$ & 3.1 \\
\hline Sex of household head (Female) & $1(1.8)$ & $20(9.8)$ & $35(57.4)$ & $92.9 * * *$ \\
\hline Marital status (Single, widowed or divorced) & $0(0)$ & $21(7.9)$ & $36(59.0)$ & $113.8 * * *$ \\
\hline Family size ( $>5$ persons $)$ & $50(89.3)$ & $199(74.8)$ & $25(41.0)$ & $38.0 * * *$ \\
\hline Farm experience ( $<10$ years) & $8(14.3)$ & $133(50)$ & $55(90.2)$ & $67.8 * * *$ \\
\hline Dependancy ratio $(>1)$ & $33(58.93)$ & $172(64.66)$ & $28(45.90)$ & $7.43 * *$ \\
\hline Literacy status (Illiterate) & $31(55.4)$ & $129(48.5)$ & $26(42.6)$ & 1.9 \\
\hline Early warning information (No) & $45(80.4)$ & $201(75.7)$ & $50(82.0)$ & 1.5 \\
\hline Participation in social institutions $(<3)$ & $25(44.6)$ & $152(57.1)$ & $34(55.7)$ & 2.9 \\
\hline Non-farm income (No) & $40(71.43)$ & $226(84.96)$ & $52(85.25)$ & $6.3 * *$ \\
\hline Income (below absolute poverty level) & $16(28.6)$ & $126(47.4)$ & $45(73.8)$ & $24.5^{* * *}$ \\
\hline Livestock size $(<5$ TLU) & $15.45(9.6)$ & $9.05(4.2)$ & $5.0(3.6)$ & $58.8 * * *$ \\
\hline Percived land tennure security (No) & $28(50.0)$ & $31(49.3)$ & $31(31.2)$ & $6.9 * * *$ \\
\hline Access to credit (No) & $9(16.1)$ & $33(12.4)$ & $8(13.1)$ & 0.6 \\
\hline Farm land size $(<0.75 \mathrm{ha})$ & $2.34(1.1)$ & $1.78(1.3)$ & $1.1(1.0)$ & $17.5 * * *$ \\
\hline Distance from the nearest main road $(>1 \mathrm{hr})$ & $17(30.4)$ & $29(10.9)$ & $5(8.2)$ & $6.8 * * *$ \\
\hline Access to agricultural axtension (No) & $9(16.1)$ & $33(12.4)$ & $8(13.1)$ & 0.6 \\
\hline $\begin{array}{l}\text { Percived plot-level severe cropland degrdation } \\
\text { (yes) }\end{array}$ & $13(23.2)$ & $63(23.7)$ & $7(11.5)$ & 4.5 \\
\hline Plot level cropland productivity decline $(>25 \%)$ & $44(81.5)$ & $187(70.3)$ & $28(45.9)$ & $18.8 * * *$ \\
\hline Wildlife conflict (Yes) & $36(64.3)$ & $162(60.9)$ & $30(49.1)$ & 3.5 \\
\hline Perceived change in temperature (Yes) & $52(92.9)$ & $246(92.5)$ & $40(65.6)$ & $36.0 * * *$ \\
\hline Perceived rainfall decrease below average (Yes) & $52(92.9)$ & $241(90.6)$ & $40(65.6)$ & $29.4 * * *$ \\
\hline
\end{tabular}

Source: Own computation, 2019

\subsection{Determinants of households' vulnerability}

Before fitting the model, multicollinearity test among explanatory variables was conducted using the variance inflation factor (VIF). The computed mean VIF value for all explanatory variables was 1.69 and all the VIFs are less than 10 implying that there is no multicollinearity problem among explanatory variables.

The log-likelihood ratio of the ordered logistic regression model has chi-squared value 304.27 which is significant at less than $1 \%$ probability level revealed that the model rejected the null hypothesis that the explanatory power of the model is equivalent to zero. The model Pseudo- $\mathrm{R}^{2}$ explained $48.04 \%$ of the variations in the dependent variables are due to the explanatory variables. Among the 22 selected and hypothesized independent variables included in the model, 14 variables were found to have a significant influence on households' vulnerability to the impacts of land degradation. The variables that significantly affected vulnerability to the impacts of land degradation are age of the household head, sex of the household head, marital status, family size, farm experience, dependency ratio, social participation, livestock ownership and farm size, land security perception, distance to the nearest main road and crop yield reduction due to land degradation. The discussions about the significant variables under each vulnerability context are given below.

\subsubsection{Social vulnerability}

Being aged $(+64)$ decreases the $\log$ odds of reporting higher vulnerability status (from low, moderate to higher) by 1.9 points holding other variables constant. The odds of high vulnerability versus the combined moderate and low categories are 0.15 lower, given that all the other variables in the model are held constant. This result is contrary to the prior expected sign as older households have poor health to supply active labor that agriculture needs. In this case, older headed households have accumulated wealth in the form of land and livestock that help them adapt to the impact of land degradation vulnerability that youth farm households mostly lack, because, there is no agricultural land distribution that affects all agricultural activities in the area (Temesgen et al., 2008).

The log odds of being highly vulnerable to the impact of land degradation will increase by 1.85 points for female-headed households after controlling for other variables in the model. The odds of high vulnerability versus the combined moderate and low categories are 6.35 higher, given that all the other variables in the model are held constant. This result is consistent with the theories and prior expected results as female-headed households usually lack the emergent sustainable livelihood resources including entitlement compared to male household heads. The result is inconsistent with the result of Opiyo et al., (2014) conducted a study on household vulnerability to climateinduced stresses in pastoral rangelands of Kenya the implications for resilience programming. 
Similarly, single-headed households including divorced and widowed were found to be more vulnerable to the impact of land degradation compared to married households. For households whose heads are married, the odds of highly vulnerable versus the combined moderate and lower vulnerability status categories are 15.49 times more, given other variables in the model held constant. This might be because most single-headed households have less family size compared to a couple of household heads. This result is consistent with the prior expected sign and the result of Opiyo et al. (2014) in Kenya.

Family size was positively and significantly related to vulnerability to the impact of land degradation at less than one percent probability level. For households whose family size is greater than five, the odds of highly vulnerable versus the combined moderate and lower vulnerability status categories are 0.22 times higher, given other variables in the model held constant. This result is consistent with the prior expectation that households with higher family sizes are more vulnerable to the impact of land degradation in Ethiopia in general and in the study area in particular.

The issue of the role of population growth and family size in development in general and adaptation to the impact of land degradation, vulnerability reduction, and community resonance process, in particular, remain unresolved. Large family size is assumed to be the source of labor, skills and strong social capital to adapt to changing environments including land degradation and climate change/variability. Larger family size might be positively related to vulnerability to the impact of land degradation when the number of dependencies is higher (Amuzu et al., 2018). This reality continues in spite of the growing literature worldwide and also in Ethiopia providing confirmation on the negative impact of large family size. The study conducted by Tesso (2013) in the West Arsi zone of Ethiopia confirmed this result.

Households who participated in less than three social institutions (informal or formal) were found to be less vulnerable to the impact of land degradation compared to households participating in more than three social institutions at less than one percent significance level. For households whose heads participated in less than three social organizations, the odds of highly vulnerable versus the combined moderate and lower vulnerability status categories are 1.69 times higher, given other variables in the model held constant (Alhassan and Kuwornu, 2018). This implies that social participation aggravates households' vulnerability to the impact of land degradation. The probable reason might be that the majority of the social institutions in the study area were not focusing on rural development, but are burial and pray events that consume time and resources. The result is contrary to the theoretical expectation and research findings (Sujakhu et al., 2019). Similarly, farm households who do not have access to extension service were found to be less vulnerable to the impact of land degradation compared to others at less than $1 \%$ probability level.

\subsubsection{Economical Vulnerability}

The result of the ordered logistic regression result showed that households farm households who had livestock size less than five TLU were found to be more vulnerable to the impact of land degradation compared to households who have more than five TLU. The odds ratio result showed that households who owned less than five livestock units were 3.4 times more vulnerable than households owned greater than five TLU. This result is consistent with the findings of Obert (2017) and Opiyo et al. (2014).

Distance to the main road in minutes was positively and significantly related to the impact of land degradation vulnerability in the central Omo Gibe basin at a $1 \%$ probability level. The odds ratio result showed that households who travel more than one hour to the nearest main road were 0.98 times more vulnerable than households who travel less than an hour. Improving access to the main road improves farmers' production and productivity, marketing access at less cost and increases farmers' profit margin, the incentive of market participation which improves the adaptive capacity of the farm households in coping vulnerability (Amuzu et al., 2018).

For households who have no access to extension service, the odds of highly vulnerable versus the combined moderate and lower vulnerability status categories are 4.68 times higher, given other variables in the model held constant. The odds ratio result showed that farmers who have no access to extension service were 4.68 times more vulnerable to the impacts of land degradation than farmers who have contact with extension agents. This result was inconsistent with the prior expectation. This might be to the fact that agricultural extension service nonuser farmers extension lacks information technology how land degradation is improved or degradation is reduced, use of agricultural input and techniques of productivity on the plot land increased that increase households' adaptive capacity and resilience (Aymone and Ringler, 2010).

Farmers who were not secured in their land tenure were positively and significantly affected by the impact of land degradation vulnerability at less than one percent significance level. The odds ratio result showed that less secure about their land was 2.48 times more vulnerable compared to farmers who believed security in their land. Land tenure security is the most important in the long term investment and expectation to long term return on it. However, in Ethiopia, the land is a common property of Ethiopian people's nations and nationalities so that farmers have only user rights. This prevents farmers from investing the long term structural soil and water conservation, small scale irrigation construction and ditch building and many others influence land fertility and productivity that decrees farmers' adaptive capacity increases vulnerability. Gbetibouo and Ringler (2009) had a similar result. 
In a similar way, plot size also affected farmers' vulnerability to the impact of land degradation. Farmers who have less than 0.75 hectares are positively and significantly related to the impact of land degradation. Households having less than one hectare has more 2.5 more likely vulnerable to the impact of land degradation. If the land size is increased by one unit being other factors affecting vulnerability, the probability of households vulnerable to the impact of land degradation decreases by $2 \%$. This implies that land size is the most important factor in affecting households' vulnerability (Gbetibouo and Ringler, 2009).

\subsubsection{Biophysical vulnerability}

Plot level yield reduction was also the most important biophysical factors affecting households' sensitivity to the impact of land degradation vulnerability. Indicated in the Table below, farmers perceived their crop productivity reduced by more than $10 \%$ since started cultivation was positively and significantly $(\mathrm{P}<0.001)$ related to land degradation impacted vulnerability.

The result of the odds who perceived their yield reduced more than $10 \%$ was $11 \%$ times more vulnerable compared to farmers who are perceived lower than $25 \%$ reduction. The marginal effect result also showed that as farmers whose cropland plot yield reduction increased to more than $10 \%$ increased in one percent, their vulnerability will increase by $2 \%(\mathrm{P}<0.001)$. This result is in agreement with the work of (Praveen et al., 2016) reduction increased vulnerability. This might be because yield reduction increases in farmers' food insecurity, poverty, and instability of farmers' income to purchase agricultural input that further affects adaptive capacity.

As inducted in Table 8, farmers who perceived their cropland plots were degraded severely or extremely were negatively and significantly vulnerable compared to farmers who perceived degradation severity levels. The result of the odds ratio showed farmers perceived their croplands were degraded highly $48 \%$ less vulnerable than lowerlevel degradation perceived farmers. The marginal effect analysis result showed that as farmers' perception of their land is highly degradation increase in one categorical unit, the probability of farmers affected by land degradation induced vulnerability $1 \%$ being other factors affecting vulnerability constant. This result is consistent with the prior expected results and the work of Webb et al. (2017) showed that higher land degradation has a more social, economic and environmental impact on households' vulnerability.

Table 8. The ordered logistic regression result

\begin{tabular}{|c|c|c|}
\hline Explanatory variables & Coefficient & Odds ratio \\
\hline \multicolumn{3}{|l|}{ 1. Social vulnerability } \\
\hline Age of the households head $(+64)$ & $-1.90 * *(0.81)$ & 0.15 \\
\hline Sex of the household head (Female) & $1.85 * *(0.84)$ & 6.35 \\
\hline Marital status (Single, divorced or widowed) & $2.74 * * *(0.89)$ & 15.49 \\
\hline Family size $(>5)$ & $-1.52 * * *(0.42)$ & 0.22 \\
\hline Farm experience ( $<10$ years $)$ & $2.04 * * *(0.42)$ & 7.68 \\
\hline Dependency $\operatorname{ratio}(>1)$ & $-0.65 *(0.34)$ & 0.52 \\
\hline Literacy status (Illiterate) & $-0.45 * *(0.17)$ & 0.49 \\
\hline Early warning information (No) & $-0.02(0.37)$ & 0.98 \\
\hline Participation in social institutions $(<3)$ & $0.53 *(0.31)$ & 1.69 \\
\hline \multicolumn{3}{|l|}{ 2. Economic vulnerability } \\
\hline Non-farm income (No) & $-0.09(0.41)$ & 0.92 \\
\hline Annual income (<11000Birr) & $0.50(0.35)$ & 1.66 \\
\hline Livestock size $(<5$ TLU $)$ & $1.25 * * *(0.36)$ & 3.49 \\
\hline Perceived land tennure security (No) & $0.91 * * *(0.34)$ & 2.48 \\
\hline Access to credit (No) & $-0.05(0.44)$ & 0.95 \\
\hline Farm land size $(<0.75 \mathrm{ha})$ & $0.95 * * *(0.33$ & 2.5 \\
\hline Distance to the nearest main road ( $>1$ hour) & $0.02 * * *(0.01)$ & 0.98 \\
\hline Access to agricultural axtension (No) & $1.5 * * *(0.4)$ & 4.68 \\
\hline \multicolumn{3}{|l|}{ 3. Potential impact (Exposure/sensitivity) } \\
\hline Plot level cropland productivity decline $(>25 \%)$ & $0.40 * * *(0.13)$ & 0.02 \\
\hline Percived cropland degrdation (Yes) & $-0.65 * *(0.33)$ & 0.52 \\
\hline Human-wildlife conflict (Yes) & $0.04(0.32)$ & 1.05 \\
\hline Perceived change in temperature (Yes) & $-0.7(0.5)$ & 0.49 \\
\hline Perceived change in rainfall (Yes) & $-0.5(0.7)$ & 0.63 \\
\hline Constant 1 & $0.04 * *(0.1)$ & \\
\hline Constant 2 & $58.5 * * *(81.3)$ & \\
\hline LR chi2(23) & $306.9 * * *$ & \\
\hline Pseudo- $\mathrm{R}^{2}$ & $48.9 \%$ & \\
\hline Observations & 383 & \\
\hline
\end{tabular}

Value in the brackets is standard errors. ${ }^{* *}, * *$ and $*$ at $1 \%, 5 \%$ and $10 \%$, respectively.

Source: Own computation, 2019. 


\section{Conclusion and Policy Implications}

This study integrated social and economic (adaptive capacity), and biophysical (the ending) vulnerability to asses the total integrated micro-level farm households' vulnerability to the impact of land degradation in the Central Omo-Gibe basin, southwestern Ethiopia. The study was based on the composite indicators PCA statistically different weighting approach to avoid equal weight bias. The KMO sample adequacy, Bartlett's test of fitness and Cronbach's alpha test of consistency of the dataset showed that PCA based indicator weighting approach was appropriate for analysis.

The result of the analysis indicated that $44.91 \%, 39.16 \%$ and $15.93 \%$ of the sample households were categorized as less, moderately and highly vulnerable to the impact of land degradation, respectively. The highly vulnerable households need emergent assistance to pull them out of vulnerability. The chi-squared value indicated that there is a statistically significant difference in vulnerability to the impact of land degradation among farm households across districts. Konta is the most vulnerable district followed by Tocha and Issera districts in this order.

The ordered logistic regression model result showed that out of the total of 22 variables entered into the model, 15 variables were found to be significantly affecting vulnerability to the impact of land degradation. These include: age, sex, marital status, family size, Farm experience, dependency ratio, literacy status, and social participation were social variable affecting vulnerability while livestock ownership, extension service, land security, land size and distance to the nearest main road are the most economic variables affecting households' vulnerability to the impact of land degradation. Furthermore, cropland productivity reduction and plot-level land degradations are sensitivity and exposure variables that affected households' vulnerability to the impact of land degradation in the study area.

Therefore, policymakers and local development practitioners should give priority to highly vulnerable households based on improving agricultural training for farmers, gender empowerment, improving social linkages and social institutions, improving family planning, strengthen soil and water conservation, improving education syllabus that helps to natural resource conservation. Furthermore, improving livestock production and productivity, land tenure security, access to the nearest main road for agricultural produces market are some of the most important policy options to reduce farm households' vulnerability, increase adaptive capacity and resilience in the central Omo - Gibe Basin in southwestern Ethiopia.

\section{Acknowledgment}

The authors are grateful to the respondent farmers for their willingness to provide data. We are also grateful to Haramaya University and Ethiopian Wildlife Conservation Authority (EWCA) for their support. Lastly, the authors wish to thank anonymous reviewers.

\section{References}

Aymone, G. G. and C. Ringler. (2010). Mapping South African Farming Sector Vulnerability to Climate Change and Variability. Natural Resources Forum, 34: 175-87.

Bekabil, Urgessa Tilahun. (2014). farmers' perception and adaptation to climate change : Heckman's. Ethiopian Journal of environmental studies and management, 7(1): 832-39.

Berry, Leonard, J. Olson, and D. Campbell.( 2003). Assessing the Extent, Cost and Impact of Land Degradation At the National Level: Findings and Lessons Learned From Seven Pilot Case Studies. working paper on Commissioned by Global Mechanism with support from the World Bank; 1-25.

Brown, D., Rance Chanakira, R., Chatiza, K., Dhliwayo, M., Dodman, D., Masiiwa, M., Muchadenyika, D., Prisca Mugabe, P. and Zvigadza, S .(2012). Climate Change Impacts, Vulnerability, and Adaptation in Zimbabwe.

CSA. 2013. Population Projections for Ethiopia.

Delong, Catherine, Richard Cruse, and John Wiener. (2015). The Soil Degradation Paradox: Compromising Our Resources When We Need Them the Most. Journal of Sustainability 7(1): 866-79.

Deresa, Feyera, and Tsetadirgachew Legesse. (2015). Cause of Land Degradation and Its Impacts on Livelihoods of the Population in Toke Kutaye Woreda, Ethiopia. International Journal of Scientific and Research Publications, 5(5): 1-9.

Deressa, Temesgen, Rashid M. Hassan, and Claudia Ringler. (2008). Measuring Ethiopian Farmers 'Vulnerability to Climate Change Across Regional States. International Food Policy Research Institute (IPFRI) discussion paper No. 00689.

Gashaw, Temesgen, Amare Bantider, and Hagos G. Silassie.( 2014). Land Degradation in Ethiopia: Causes, Impacts and Rehabilitation Techniques. Journal of Environment and Earth Science, 4(9): 98-104.

Gbetibouo, Glwadys Aymone, and Claudia Ringler. (2009). Mapping South African Farming Sector Vulnerability to Climate Change and Variability: A Subnational Assessment. Pp. 1-28 in Mapping South African Farming Sector Vulnerability to Climate Change and Variability: A Subnational Assessment.

Grothmann, Torsten, Maximilian Petzold, Patrick Ndaki, Vincent Kakembo, Bernd Siebenhüner, Michael Kleyer, 
Pius Yanda, and Naledzani Ndou. (2017).Vulnerability Assessment in African Villages under Conditions of Land Use and Climate Change: Case Studies from Mkomazi and Keiskamma. Sustainability, 9(6): 1-30.

Madu, By Ignatius A. 2012. Spatial Vulnerability to Rural Nigeraia.

Mavhura, Emmanuel, Bernard Manyena, and Andrew E. Collins. (2017). An Approach for Measuring Social Vulnerability in Context: The Case of Flood Hazards in Muzarabani District, Zimbabwe. Geoforum, 86: 10317.

Moret, Whitney. ( 2014). Vulnerability Assessment Methods. 1-8.

Nani M., Sujakhu S. Ranjitkar, Jun He Dietrich Schmidt-Vogt, Yufang Su and Jianchu Xu. (2019). Assessing the Livelihood Vulnerability of Rural Indigenous Households to Climate Changes in Central Nepal, Himalaya. Journal of Sustainability, 11(10): 2-18.

Obert, Jiri. (2017). Contextual Vulnerability of Rainfed Crop-Based Farming Communities in Semi-Arid Zimbabwe edited by M. P. L. International Journal of Climate Change Strategies and Managemen, 9(6): 777-89.

Olusola, Akeem. (2014). Climate Change Effects on Household Agric-Economy and Adaptive Responses among Agricultural Households in Nigeria. in Famine Early Warning Systems Network, Pp. 1-18.

Opiyo, Francis E. O., Oliver V Wasonga, and Moses M. Nyangito. (2014a). Measuring Household Vulnerability to Climate-Induced Stresses in Pastoral Rangelands of Kenya : Implications for Resilience Programming, 115.

Opiyo, Francis E. O., Oliver V Wasonga, and Moses M. Nyangito. (2014b). Measuring Household Vulnerability to Climate-Induced Stresses in Pastoral Rangelands of Kenya: Implications for Resilience Programming. Journal Pastoralism: Research, Policy, and Practice, 10(4): 1-15.

Qaisrani, Ayesha, Muhammad Awais, Umar Ghamz, E. Ali Siyal, and Kashif Majeed. 2018. What Defines Livelihood Vulnerability in Rural Semi-Arid Areas? Evidence from Pakistan. Journal of Earth Systems and Environment, 2(3): 455-75.

Saguye, Tesfaye Samuel. (2017a). Analysis of Farmers' Perception of the Impact of Land Degradation Hazard on Agricultural Land Productivity in Jeldu District in West Shewa Zone, Oromia, Ethiopia. Journal of Agricultural Extension and Rural Development, 9(6): 111-23.

Saguye, Tesfaye Samuel. (2017b). Analysis of Farmers' Perception of the Impact of Land Degradation Hazard on Agricultural Land Productivity in Jeldu District in West Shewa Zone, Oromia, Ethiopia. Journal of Natural Science Research, 9: 111-23.

Senapati, Asis Kumar. ( 2019). Assessing the Vulnerability of Agricultural Households to Covariate and Idiosyncratic Shocks : A Case Study in Odisha, India. Climate and Development (0): 1-15.

Sujakhu, Nani Maiya, Sailesh Ranjitkar, Rabin Raj Niraula, Muhammad Asad Salim, Arjumand Nizami, Dietrich Schmidt-Vogt, and Jianchu Xu. 2018. Determinants of Livelihood Vulnerability in Farming Communities in Two Sites in the Asian Highlands. Water International, 43(2): 165-82.

Admasu A. and Zelalem. (2015). Defensive Walls under Threat: Examining the Status of the Great Medieval Defensive Walls of Dawuro People in Southern Ethiopia. Journal for Studies in Management and Planning, 01(09): 61-79.

Teshome, Menberu. (2016). Rural Households' Agricultural Land Vulnerability to Climate Change in Dembia Woreda, Northwest Ethiopia. Journal of Environmental Systems Research, 5(14): 2-18.

Tesso, Gutu. (2013). Individual Level Vulnerability to Climate Change Impact among Crop Dependent Communities of Western. Journal of Agricultural Economics and Development, 2(9): 356-70.

Tesso, Gutu, Bezabih Emana, and Mengistu Ketema.(2012). Analysis of Vulnerability and Resilience to Climate Change Induced Shocks in North Shewa, Ethiopia. Journal of Agricultural Sciences, 3(6): 871-88.

Tofu, Daniel Assefa and Deressa Gadisa Dedefa. (2018). Farm Household Vulnerability to Climate Change and Its Determinants : The Case of Ada'a Berga District of West Shewa, Ethiopia. Journal of Scientific Research and Reports, 21(3): 1-17.

Tsue, Peter Terfa, Noble Jackson Nweze, and Chukwuemeka Uzoma Okoye. 2014. Vulnerability of Farming HVulnerability of Farming Households to Environmental Degradation in Developing Countries: Evidence from North Central Nigeria. Journal of Economics and Sustainable Development, 5(24): 206-16.

Zeleke, Terefe and Corresponding Author. (2014). The Contribution of Rural Resettlement to the Livelihoods of Settlers in Ethiopia: A Case of Essera District Resettlement Schemes in SNNPR. Public Policy and Administration Research, 4(5): 36-53.

Zenebe Gebreegziabher, Alemu Mekonnen, Rahel Deribe, Jonse Boka, and Samuel Abera. 2016. Environment for Development Mapping Vulnerability to Climate Change of the Farming Sector in the Nile Basin of Ethiopia. Discussion paper on Environment for Development, Pp. 2-23. 